\title{
Wearable Device for Women Safety Using IOT
}

\author{
B. Nivedetha ${ }^{1}$ \\ $\left\{\right.$ bn.eee@psgtech.ac.in $\left.{ }^{1}\right\}$ \\ Assistant Professor, EEE, PSG College of Technology ${ }^{1}$
}

\begin{abstract}
Women are facing lot of critical problems in the nation at many occurrences and to ensure the protection of women a wearable device is proposed using Internet of Things (IoT). In the existing system, the location of the person is identified once the button is manually pressed and the message is send to the pre-set contacts. In this work, different sensor like pulse rate sensor and temperature sensor are used for detecting the abnormal pulse rate and temperature. Global Positioning System identifies the exact location of the women in problem and forwards the locality details as emergency message to preset contacts and police control room using GSM. In proposed IoT based wearable device which helps to continuously monitor values of different sensor and automatically the message is send to the pre-set contacts. In case if the device is triggered accidentally it can be turn off by pressing the reset button. The wearable device can be a watch, stun ring, or affixed in apparels.
\end{abstract}

Keywords: Wearable device, Women safety, IoT, Arduino, GSM, GPS, Sensor.

\section{Introduction}

Women are becoming more independent day by day and they are keeping pace with the upcoming trends. But it is so difficult for them to come out of the home at night time or go to any isolated areas because of the sexual harassment against them is increasing daily.Both women and young girls are facing problems [1] even though the technology is growing. Society should be aware of giving importance to women and they should be properly protected. In situations if women want to go out with friends during night or in case they are alone in house this device will guard them, reduce risk of fear and bring assistance when they need it.

\section{Block Diagaram}

Arduino Nano holds an important function in the women safety kit [8]. Figure 1 represents the block diagram with heart rate sensor; temperature sensor and a manual switch are connected to Arduino Nano. All these devices are connected to the mobile application using the internet through the Wi-Fi transceiver [2]. A stun device is also used as a selfdefence module and that is also connected to Arduino Nano through Wi-Fi transceiver module. Android Application [11] is developed and connected to Internet which is sending the message to the contacts using Wi-Fi transceiver module [3]. 


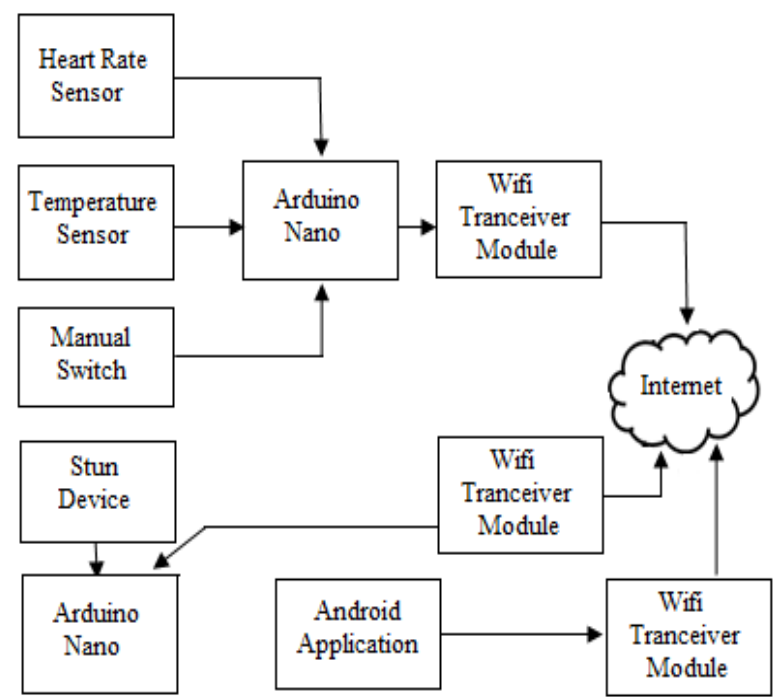

Fig 1: Block Diagram of wearable device

\section{Experimental Setup}

The various hardware equipment's employed in this safety system are as follows:

\subsection{Arduino Nano:}

Arduino Nano is a tiny, absolute board which is very easy to configure and similar to atmega328p as in Figure 2. Mini-B USB connection is used for powering; pin 30 is given an unregulated external power supply of $6-20 \mathrm{~V}$, or pin 27 is given $5 \mathrm{~V}$ regulated external power supply. Automatically power source is selected such that it reaches the highest voltage source.

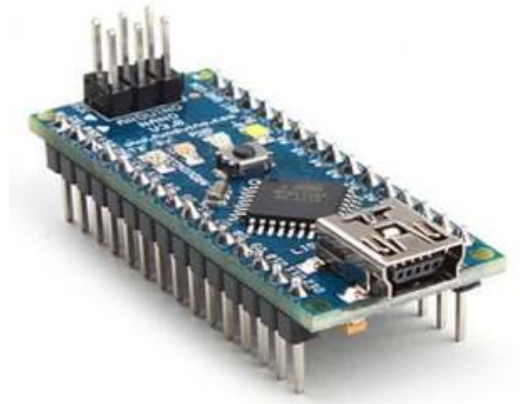

Fig 2: Arduino Nano

\subsection{Heart Rate Sensor:}

Heart rate sensor as shown in Figure 3 monitors the heart beat and is available in a variety of bands. Nowadays models in the market are available with inbuilt sports watches, gym equipment such as treadmills. There are few sports watches which monitor heart rate in the famous brands like Reebok, Nike, and many more. There are different athletic watches with many types to monitoring during exercise [9] like running and cycling heart rate monitor. 


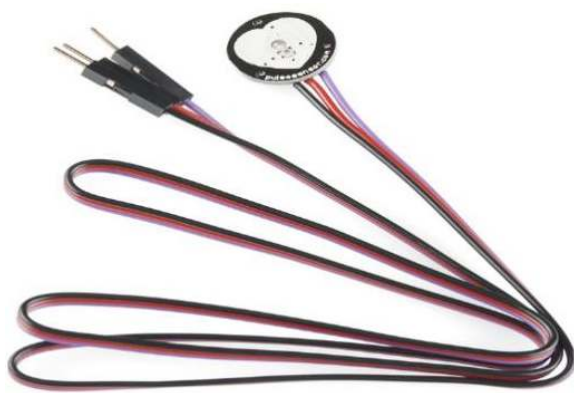

3.3 Temperature Sensor:

Fig 3: Heart rate sensor

Thermistor is another type of temperature sensor as shown in Figure 4 which has been decided to use in our project, where name indicates all sensitive resistor. Thermistors are unique resistors and they vary their physical resistance value while exposed to alteration in temperature. Thermistors are made up of ceramic material like cobalt, nickel, etc, in metal oxide technology. The major benefit is their accuracy and repeatability in reading if the temperature changes over snap action method.

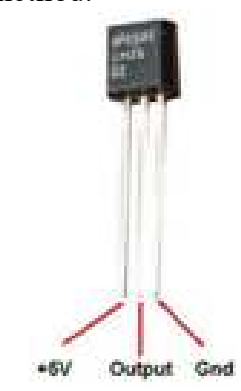

3.4 Manual Switch:

Fig 4: Temperature sensor

The physical starter is generally an "ON-OFF" switch with overload safety. In case if the device is triggered accidentally it can be turn off by pressing the manual button.

3.5 Stun Device:

Stun gun device [10] acts as a protection device against various attacks. This gun utilizes higher voltage energy and immediately stop the attacker. When the muscle gets in direct contact with the energy the person cannot move further. Attacker will not be able to do any task for sometime and it will not affect his internal organs. Nearly within three seconds the person will loose muscle function, failure in balance and unsteadiness. Stun gun normally use a high voltage, yet the effects are very less. While caring the stun gun women can feel safer and neutralize an attacker if needed.

\subsection{Wi-Fi Transceiver Modules:}

Wi-Fi transceiver module [5] as shown in Figure 5 is used to connect all the interfaces through Wi-Fi. And it is Arduino supported which is light weight and consumes minimal power usage. 


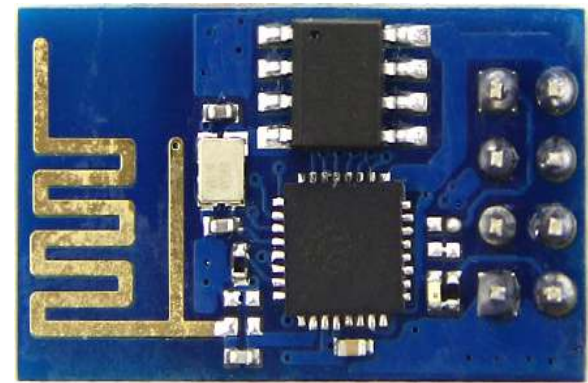

Fig 5: Wi-Fi Transceiver

\section{Features of GSM}

The salient features of GSM technology [3] makes it highly usable and reliable mobile communication in today's world.

- GSM is available withservices like fax, mail, voice mail, voice data and SMS.

- GSM provides more secured and protected communication between networks from intruders and frauds.

- GSM technology changed the usage of mobile phones.

- GSM allows the mobile user to use above its limits and facilitate user to communicate across the continents.

\section{Wearable Device}

In Figure 6, [4] an Arduino Nano, temperature sensor, heart rate sensor, Wi-Fi transceiver and a manual switch is connected. The 9V power supply is given. A PCB board is used in which all the wires are solder in it and all the wires from there are connected to other components. 


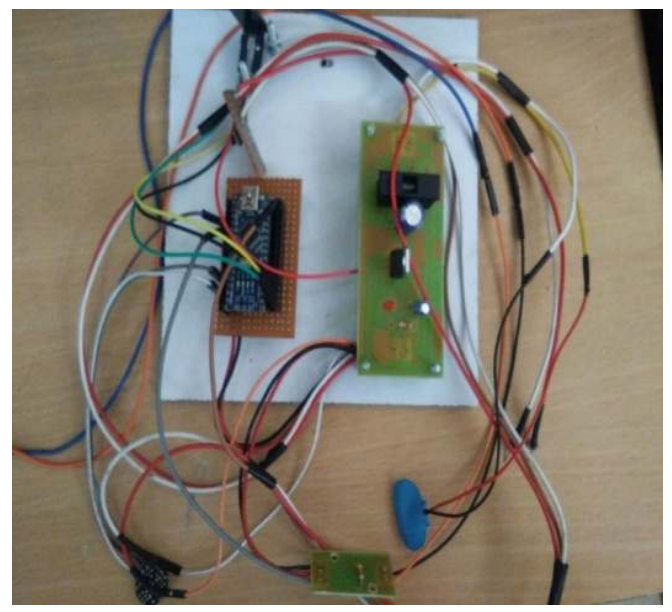

Fig 6: Wearable device

Figure 7 is the application that has been developed to be installed in mobile phones [6]. After setting the preset contact, click on start.

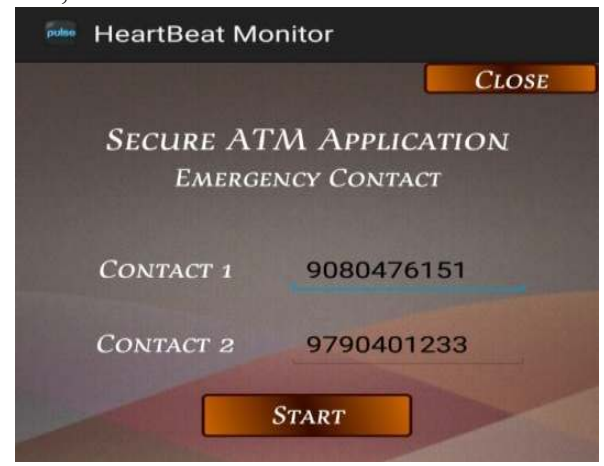

Fig 7: Main Application screen

Temperature and heart rate are continuously monitored as shown in Figure 8. In abnormal condition the message is send to the preset contact. In case, if the button is accidentally triggered it can be turned off using the reset button. 


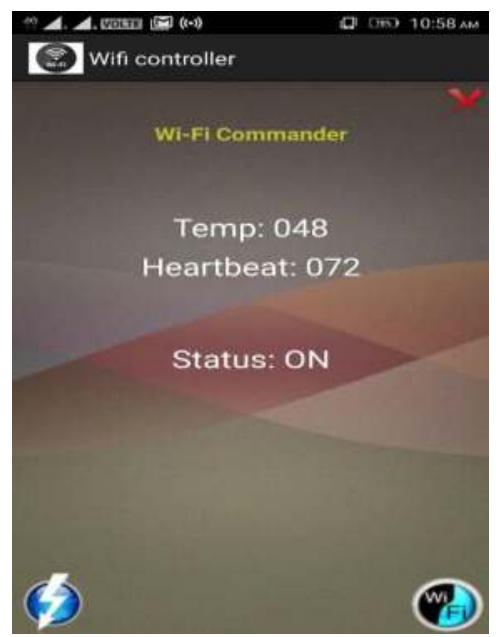

Fig 8: Status of the temp and heart rate sensor

- Heart rate during rest differ to each person based upon various elements like age, tallness, physical weight and wellness [12]. Table 1 indicates heart rate ranges of women for various age groups.

Table 1 Heart rate ranges of women

\begin{tabular}{|l|l|l|l|l|l|l|}
\hline \multicolumn{2}{|l|}{ WOMEN'S RESTING HEART RATE CHART } \\
\hline AGE & $\mathbf{1 8 -}$ & $\mathbf{2 6 -}$ & $\mathbf{3 6 -}$ & $\mathbf{4 6 -}$ & $\mathbf{5 6 -}$ & $\mathbf{6 5 +}$ \\
& $\mathbf{2 5}$ & $\mathbf{3 5}$ & $\mathbf{4 5}$ & $\mathbf{5 5}$ & $\mathbf{6 5}$ & \\
\hline Athlete & $54-$ & $54-$ & $54-$ & $54-$ & $54-$ & $54-$ \\
& 60 & 59 & 59 & 60 & 59 & 59 \\
\hline Excellen & $61-$ & $60-$ & $60-$ & $61-$ & $60-$ & $60-$ \\
t & 65 & 64 & 64 & 65 & 64 & 64 \\
\hline Good & $66-$ & $65-$ & $65-$ & $66-$ & $65-$ & $65-$ \\
& 69 & 68 & 69 & 69 & 68 & 68 \\
\hline Above & $70-$ & $69-$ & $70-$ & $70-$ & $69-$ & $69-$ \\
Av & 73 & 72 & 73 & 73 & 73 & 72 \\
\hline Average & $74-$ & $73-$ & $74-$ & $74-$ & $74-$ & $73-$ \\
& 78 & 76 & 77 & 77 & 77 & 76 \\
\hline Below & $79-$ & $77-$ & $78-$ & $78-$ & $78-$ & $77-$ \\
Av & 84 & 82 & 83 & 83 & 83 & 84 \\
\hline Poor & $85+$ & $83+$ & $85+$ & $84+$ & $84+$ & $84+$ \\
\hline
\end{tabular}

\section{Result Analysis}

The result analysis is made based on the Application and Hardware.

\subsection{APPLICATION RESULTS}


The Figure 7 shows the main screen window and figure 10,11, 12 shows the graph of the temperature sensor, heart rate sensor and emergency switch. As shown in the below figure9 the second mobile application is able to get an emergency notification with location of the person in the danger.

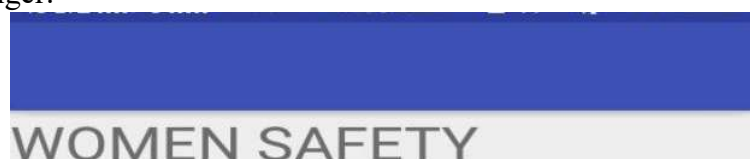

\section{WOMEN SAFETY}

\section{EMERGENCY at location}

$11.0248^{\circ} \mathrm{N}, 77.0028^{\circ} \mathrm{E}$

Fig 9: Application for nearby users

As shown in figure 10 the readings of temperature sensor are plotted using thing speak which is an open IOT platform. Figure 11 shows the readings of Heart rate sensor and Figure 12 indicates the readings of emergency switch

Field 1 Chart ए।

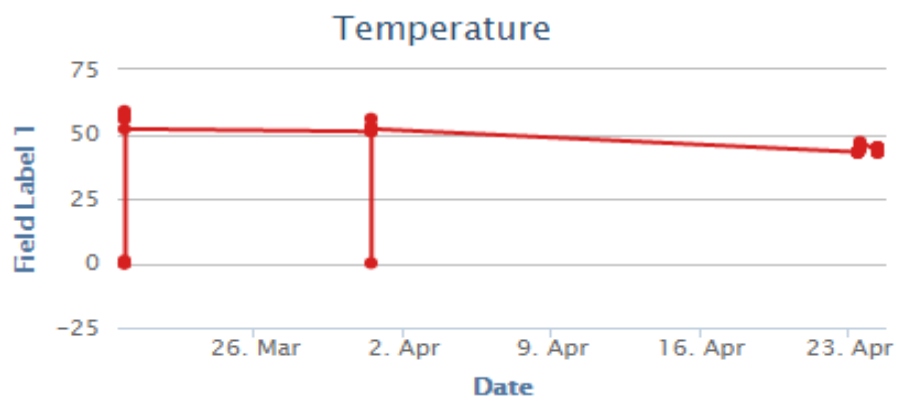

Fig 10: Graph readings on temperature
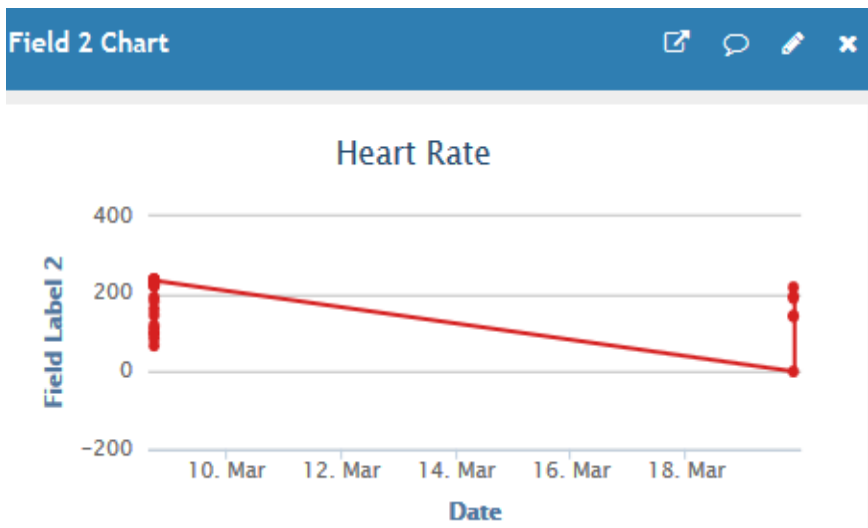

Fig 11: Graph readings on Heart rate 


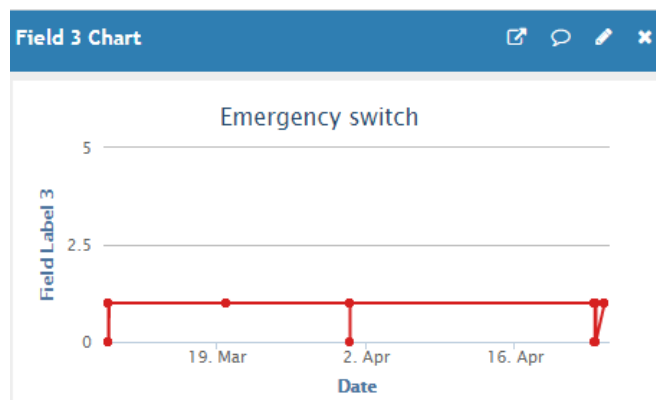

Fig 12: Graph readings on emergency switch

\subsection{HARDWARE RESULTS}

Figure 13 shows the experimental setup of the wearable device module in the proposed system. The module is able to measure the data from the required sensors, encrypts data and writes the encrypted data in the thingspeak.

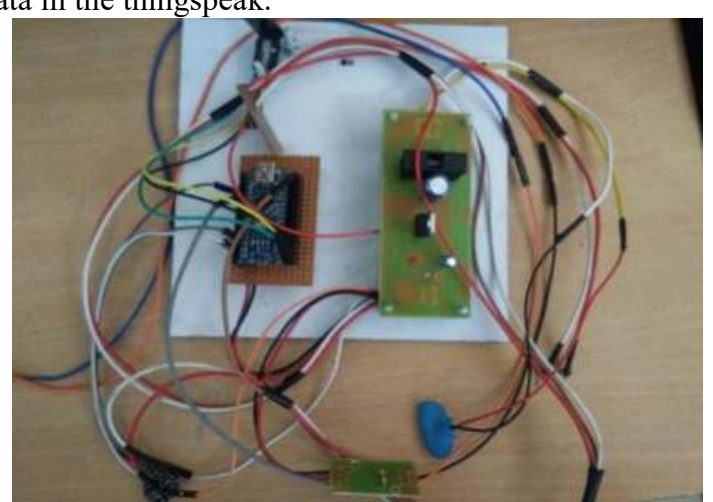

Fig 13: Wearable device module

Figure 14 shows the experimental setup of the self-defence module in the proposed system where when an emergency signal is received from the application module and when the secondary switch is on 'ON' state the LED lights up. The led can be replaced with an actual voltage booster to be used physically against potential attacker.

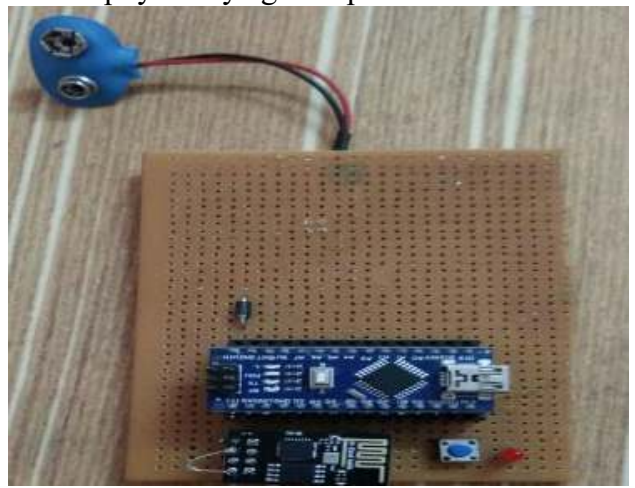

Fig 14: Stun device module 


\section{Conclusion And Future Scope}

The projected security system will help any women in danger and from any kind of attacker. The proposed system is to ensure the security of the women in the society by providing the wearable device [7] and help them to be brave at any situation and send the respective message in an encrypted format using IoT. The various challenges faced by the system could be GPS reliability, Zigbee range, power consumption, battery consumption and SMS confidentiality.

In future the security algorithm is used to transfer the affected person information in a secured manner. To reduce the weight and size of wearable device GPS and modules in phone can be utilized. Solar cell can be used as battery life of the wearable device. To improve security a small camera can be embedded on the wristband which would record the crime and serve as identification of the attacker.

\section{References}

[1] Vaijayanti Pawar, Prof. N. R. Wankhade, Dipika Nikam, Kanchan Jadhav and Neha Pathak, "SCIWARS Android Application for Women Safety", ISSN: 2248-9622 International Journal of Engineering Research and Applications, Volume 4, Issue 3, pp.823- 826, March 2014.

[2] Prof. Deepak Sharma, "All in one Intelligent Safety System for Women Security", International Journal of Computer Application volume 130, No.11, November 2015.

[3] B.Vijaylashmi, S. Renuka, Poojachennur, Sharan gowda patil "Self Defence System for Women" with location tracking and SMS alerting through GSM network and Technology volume 4, special issue 5, May 2015.

[4] Dr. Daulatrao Aher "Intelligent Safety System for Women Security" International Advanced Research Journal in Science, Engineering and Technology National Conference on Emerging trends in Electronics \& Telecommunication Engineering, volume 4, special issue 2, January 2017.

[5] Akash Wadhawane, Amir Attar, Priyanka Ghodke, Prasad petkar and shital Thokal, "IoT based Smart System for Human Safety”, International Journal of Computer Applications, 179(7), 1-3, December 2017.

[6] Saranya, K. Karthik, "Women Safety Application using Android Mobile” International Journal of Engineering Science and Computing, ISSN2321-3361, pp1317-1319, May 2015.

[7] N. Swapnali, D. Saloni, C. Amol. Bhosale "Electronic Jacket for Women Safety" International Research Journal of Engineering and Technology, Volume 4 Issue 5, ISSN: 2395 0056, May 2017.

[8] D.S. Vijayan, A. Mohan, J. Revathy, D. Parthiban, R. Varatharajan, "Evaluation of the impact of thermal performance on various building bricks and blocks: A review", Environmental Technology \& Innovation 23 (2021) 101577, https://doi.org/10.1016/j.eti.2021.101577

[9] Akanksha Chandoskar, Shraddha Chanvan "Smart Gadget for Women Safety" International Journal on Recent and Innovation Trends in Computing and Communication, Volume 4 Issue 1, ISSN: 23218169 , January 2016.

[10] D. S. Vijayan, A. Leema Rose, S. Arvindan, J. Revathy, C. Amuthadevi, "Automation systems in smart buildings: a review", Journal of Ambient Intelligence and Humanized Computing https://doi.org/10.1007/s12652-020-02666-9

[11] Shrenika N, Srivani P Badala, Sai Keerthana K S and Hamsa N, "Design of smart device with Android based Application for self defense and self-protection - A Women Security Solution", International Journal of Computer Applications, 182 (5), 29-32, July 2018.

[12] A.Alone, Ashish Manusmare "A Study based on Womens Security System" International Journal of Science, Engineering and Technology, volume 6, Issue 8, ISSN: 22787798 1241, August 2017. 